\title{
Primary classical Hodgkin lymphoma (mixed cellularity) of stomach presenting multiple polyps
}

\author{
Tadashi Terada* \\ Department of Pathology, Shizuoka City Shimizu Hospital, Shizuoka, Japan
}

Received: December 30, 2015

Accepted: March 3, 2016

Online Published: March 25, 2016

DOI: $10.5430 /$ crcp.v3n3p15

URL: http://dx.doi.org/10.5430/crcp.v3n3p15

\begin{abstract}
Backgrounds: Only a few cases of primary classical Hodgkin lymphoma (CHL) are reported previously in stomach. Case: A 77-year-old man presented epigastralgia and received an upper gastrointestinal endoscopy, which revealed multiple polyps. Biopsies (endoscopic mucosal resection) from the lesions showed proliferation of Hodgkin cells (HC) and Reed-Sternberg giant cells (RSC) mixed with non-tumorous inflammatory infiltrates composed of lymphocytes, plasma cells, neutrophils, and histiocytes. Immunohistochemically, the tumor cells (HC and RSC) showed the following immunophenotypes: cytokeratin -, CD45 +++, CD20 +++, CD10 ++. CD79a ++, CD138 +, CD3 -, CD45RO -, CD56 -, CD68 +++, CD30 -, CD15 +++, PAX5 ++, kappa-chain -, lamda-chain -, bcl-2 -, Ki67 20\%, p53 +++, vimentin +++, CD68 +++, EMA -, CEA -, S100 protein -, smooth muscle actin -, CD31-, CD34-, factor 8 -, CEA -, EBER -, EBV-latent membrane protein1 -, and EBNA2 -. Immunostainings of endothelial antigens (CD31, CD34, smooth muscle actin, and factor 8-related antigen) showed negative results. A pathological diagnosis of $\mathrm{CHL}$ of mixed cellularity type was made, and the patient has first ABVD chemotherapy and then radiation.

Conclusion: A very rare case of primary gastric CHL presenting multiple gastric polyps is reported.
\end{abstract}

Key Words: Hodgkin lymphoma, Stomach, Multiple polyps

\section{INTRODUCTION}

Primary malignant lymphoma of the gastrointestinal tract is relatively rare diagnosis. ${ }^{[1-4]}$ Most of gastrointestinal lymphomas are non-Hodgkin lymphomas (NHL), and of those the most prevalent are MALT lymphoma and diffuse large B-cell lymphoma (DLBCL). ${ }^{[1-4]}$ Hodgkin lymphomas are classified into the following two major categories: nodular lymphocyte predominant Hodgkin lymphoma and classical Hodgkin lymphoma (CHL). Hodgkin lymphoma is characterized by the presence of typical Hodgkin cells (HC) and/or Reed-Sternberg giant cells (RSC) accompanied by various fibroinflammatory non-neoplastic reactions, which sub-categorize the CHL into the following four subtypes: lymphocytic predominance, mixed cellularity, lymphocytic deletion, and nodular sclerosis. CHL occurs mainly in lymph nodes, and extra-nodal CHL is quite rare. In the stomach, only a few cases of primary CHL have been reported. ${ }^{[5-7]}$

\section{CASE REPORT}

A 77-year-old man presented epigastralgia and received an upper gastrointestinal endoscopy which revealed multiple gastric polyps measuring up to $30 \mathrm{~mm}$ in diameter (see Figure 1). Endoscopic diagnosis was hyperplastic polyps. Biopsies (endoscopic mucosal resection or endoscopic submucosal dissection) from the lesions showed proliferation of $\mathrm{HC}$ and RSC mixed with non-tumorous inflammatory infiltrates composed of lymphocytes, plasma cells, neutrophils, and histiocytes (see Figure 2A-C). An Immunohistochemical study

\footnotetext{
*Correspondence: Tadashi Terada; Email: piyo0111jp@yahoo.co.jp; Address: Department of Pathology, Shizuoka City Shimizu Hospital, Miyakami
} 1231 Shimizu-Ku, Shizuoka, Japan. 
was carried out by the use of Envision method. ${ }^{[8]}$ EBER was performed as previously reported. ${ }^{[9]}$ The immunohistochemical results of the HC/RSC are depicted in Table 1. The tumor cells (HC and RSC) showed the following immunophenotypings: cytokeratins (CKAE1/3 and CKCAM5.2) -, CD45 +++, CD20 +++ (see Figure 2D), CD10 ++. CD79a ++, CD138 +, CD3 -, CD45RO -, CD56 -, CD30 -, CD15 +++ (see Figure 2E), PAX $5++$ (see Figure 2F), kappa-chain -, lamda chain -, bcl-2 -, Ki67 20\%, p53 +++ (see Figure 2G), vimentin +++ , EMA -, S100 protein -, smooth muscle actin -, CD31 -, CD34 -, factor 8 -, CD68 +++, CEA -, EBER -, EBV-LMP1 -, EBNA2 -. The immunostainings showed that the tumor cells were not endothelial cells. The inflammatory cells mixed with the $\mathrm{HC} / \mathrm{RSC}$ were negative for p53 and showed a low Ki67 labeling index (2\%). The inflammatory cells showed a variety of markers of leukocytes, B-cell, T-cell, NK cells, plasma cells, and histiocytes, respectively, according to the populations. The epithelial cells showed no atypical features. No features of DLBCL or MALT lymphoma were seen. The diagnosis was primary gastric CHL with mixed cellularity (ICD-O-3 topography code: C42 and C77). Postbiopsy imaging and clinical examinations revealed no other tumors than the gastric lesions. The lymphoma was staged to be Ann Arbor Stage 1E, and the patient is now treated by Adriamycin-bleomycin-Vinblastine-Dacarbatzine (ABVD) chemotheraphy and then with radiation therapy.

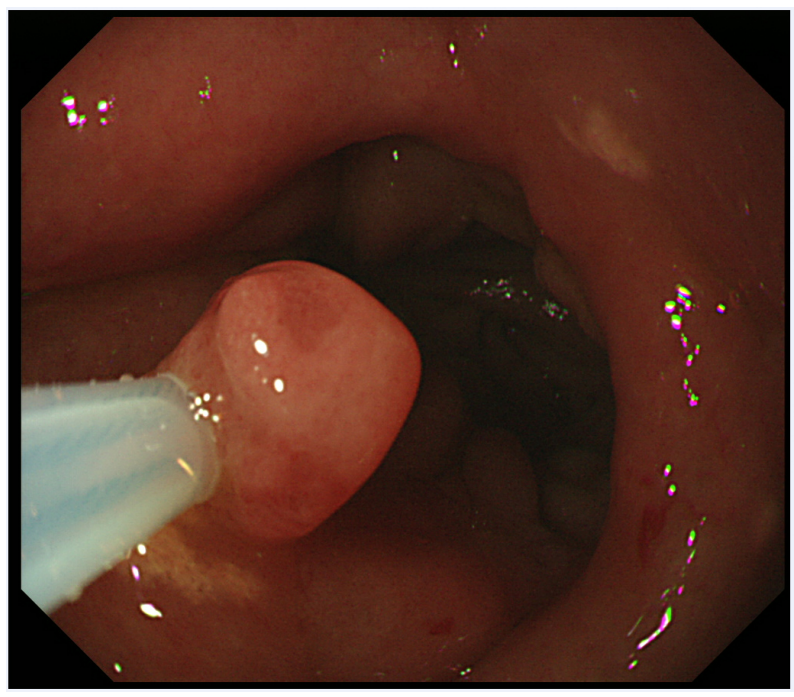

Figure 1. Upper GI endoscopy shows multiple type 1 polyps in stomach. In this figure, only one polyp was demonstrated which is subject to endoscopic submucosal dissection.

\section{Discussion}

Hodgkin lymphoma is defined only by the presence of typical HC/RSC. Although lymphoid cells (immunoblasts) resembling $\mathrm{HC} / \mathrm{RSC}$ can be seen in other lymphomas, only the presence of typical HC/RSC is the diagnostic significance. The present case showed typical HCs and RSCs, and therefore the pathological diagnosis of CHL seems correct. Although positive CD30, CD15 and PAX5 have been reported to characterize Hodgkin lymphoma, they are not necessary diagnostic criteria. For example CD30-negative Hodgkin lymphoma is present: of all Hodgkin lymphoma, CD30 is positive in $97 \%, \mathrm{CD} 15$ in $66 \%$, and PAX5 in $92 \% .{ }^{[10,11]}$ These antibodies are also not specific for HC/RSC; these also label tumor cells of immunoblasts and tumor cells of anaplastic large cell lymphoma. The malignant behaviors are reflected by high $\mathrm{Ki} 67$ labeling and p53 positivity which strengthen the diagnosis of Hodgkin lymphoma, the latter suggesting positive p53 gene mutations. ${ }^{[12]}$ Although CD30 was negative, CD15 and Pax5 were positive in the present case, which strengthen the diagnosis CHL. Recently, most cases of CHL have been reported to be of B-cell origin: the present case also showed B-cell antigens and no T/NK antigens. The subtyping of CHL in the present case was mixed cellularity. The primary site of the present case is stomach as nowhere else were tumors observed. A significant number of CHL is associated with EBV, which was negative in this case. The present case is very interesting in the point that the CHL presented as multiple gastric polyps, suggesting of multicentric occurrence, which has not been reported previously in the world literature.

Table 1. Immunohistochemistry in tumor cells (HC and RSC)

\begin{tabular}{|ll|}
\hline CKAE1/AE3 & - \\
CKCAM5.2 & - \\
CD45 & +++ \\
CD20 & +++ \\
CD10 & ++ \\
CD79a & ++ \\
CD138 & + \\
CD3 & - \\
CD45RO & - \\
CD56 & - \\
CD30 & - \\
CD15 & +++ \\
SOX5 & \\
kappa-chain & - \\
lamda chain & - \\
bcl-2 & - \\
Ki67 & $20 \%$ \\
p53 & ++ \\
vimentin & +++ \\
EMA & - \\
S100 protein & - \\
smooth muscle actin & - \\
CD31 & - \\
CD34- & \\
factor 8 & - \\
CD68 & CEA \\
EBER & ++ \\
EBV-LMP1 & - \\
EBNA2 & - \\
\hline
\end{tabular}



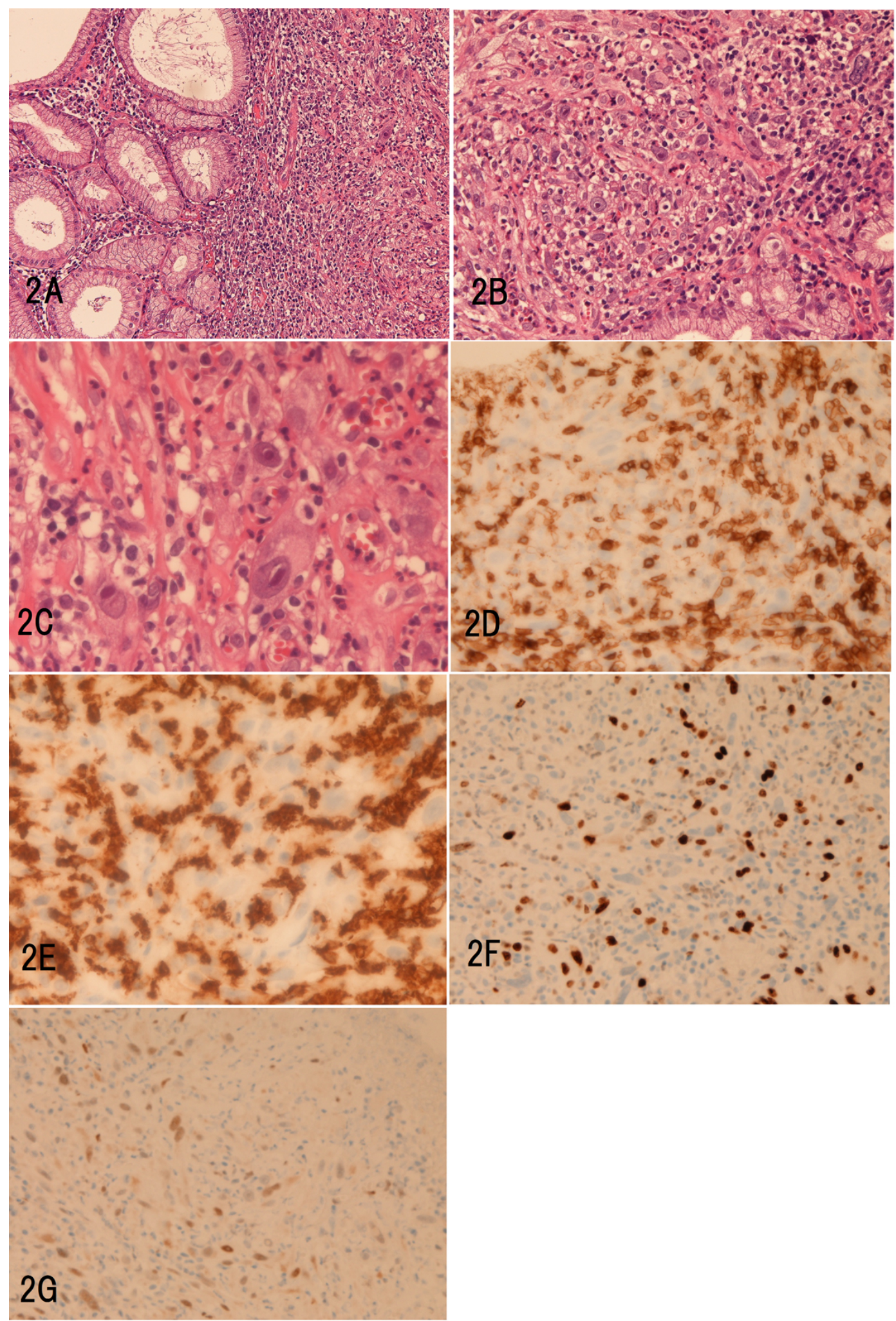

Figure 2. Histological (A-C) and Immunohistochemical (D-G) features of the gastric polyps

A: Low power view shows proliferation of atypical, large lymphoid cells with non-neoplastic infiltrates. A: $H E, \times 40 . B$, C: High power views show typical Hodgkin cells $(B)$ and Reed-Sternberg cells $(C)$ against the background of mixed cellularity lymphoid infiltrates. $B$, $\times 200$. C: $\times 400$. D-F: The Hodgkin cells and Reed-Sternberg cells are positive for CD20 (D), CD15 (E), PAX5 (F), and p53 (G). D-G: $\times 200$. 


\section{Conclusion}

\section{CONFLicts OF InTEREST Disclosure}

An extremely rare case of primary gastric CHL (mixed cellu- The author declares no conflict of interest. larity) presenting as multiple gastric polyps is reported.

\section{REFERENCES}

[1] Terada T. Extranodal marginal zone B-cell lymphoma of MucosaAssociated Lymphoid Tissue (MALT lymphoma) in ulcerative colitis. Saudi J Gastroenterol. 2014; 20: 319-22. PMid: 25253369. http://dx.doi.org/10.4103/1319-3767.141696

[2] Terada T. Extranodal marginal zone lymphoma of mucosa-associated lymphoid tissue (MALT lymphoma) of the ileum in a 35-year-old Japanese woman. Int J Clin Exp Pathol. 2013; 6: 951-6. PMid: 23638229.

[3] Terada T. Gastrointestinal malignant lymphoma: a pathologic study of 37 cases in a single Japanese institution. Am J Blood Res. 2012; 2: 194-200. PMid: 23119230.

[4] Terada T. One patient with double lymphomas: simultaneous gastric MALT lymphoma and ileal diffuse large B-cell lymphoma. Int J Clin Exp Pathol. 2012; 5: 260-3. PMid: 22558482.

[5] Ma J, Wang Y, Zhao H, et al. Clinical characteristics of 26 patients with primary extranodal Hodgkin lymphoma. Int J Clin Exp Pathol. 2014; 7: 5045-50. PMid: 25197377.

[6] Wang HW, Yang W, Wang L, et al. Composite diffuse large B-cell lymphoma and classical Hodgkin's lymphoma of the stomach: case report and literature review. World J Gastroenterol. 2013; 19: 6304-9. http://dx.doi.org/10.3748/wjg.v19.i37.6304

[7] Zettl A, Rüdiger T, Marx A, et al. Composite marginal zone B-cell lymphoma and classical Hodgkin's lymphoma: a clinicopatholog- ical study of 12 cases. Histopathology. 2005; 46: 217-28. PMid: 15693895. http://dx.doi.org/10.1111/j.1365-2559.2005 $.02046 . \mathrm{x}$

[8] Terada T, Kawaguchi M, Furukawa K, et al. Minute mixed ductalendocrine carcinoma of the pancreas with predominant intraductal growth. Pathol Int. 2002; 52: 740-6. PMid: 12685552. http: //dx.doi.org/10.1046/j.1440-1827.2002.01416.x

[9] Terada T. Epstein-Barr virus associated lymphoepithelial carcinoma of the esophagus. Int J Clin Exp Med. 2013; 6: 219-26. PMid: 23573354.

[10] Tzankov A, Zimpfer A, Pehrs AC, et al. Expression of B-cell markers in classical hodgkin lymphoma: a tissue microarray analysis of 330 cases. Mod Pathol. 2003; 16: 1141-7. PMid: 14614054. http: //dx.doi.org/10.1097/01.MP.0000093627.51090.3F

[11] Agostinelli C, Sabattini E, Gjørret JO, et al. Characterization of a new monoclonal antibody against PAX5/BASP in 1525 paraffinembedded human and animal tissue samples. Appl Immunohistochem Mol Morphol. 2010; 18: 561-72. PMid: 20697266. http: //dx.doi.org/10.1097/PAI.0b013e3181e79013

[12] Terada T, Shimizu K, Izumi R, et al. Methods in pathology p53 expression in formalin-fixed, paraffin-embedded archival specimens of intrahepatic cholangiocarcinoma: retrieval of p53 antigenicity by microwave oven heating of tissue sections. Mod Pathol. 1994; 7 : 249-52. PMid: 8008749. 